\title{
Benchmark Standards for Computing in the UK
}

\author{
Andrew McGettrick \\ Department of Computer and Information Sciences; University of Strathclyde; \\ Glasgow, Scotland \\ andrew@cs.strath.ac.uk
}

\begin{abstract}
In the UK the Government is concerned that standards should exist to ensure that all degrees awarded in institutions of higher education meet certain minimal criteria and therefore are of at least of a certain standard. To this end they have created a set of committees composed of subject experts whose task is to define the required standards for their discipline. The purpose of this paper is to outline the approach taken to address these benchmarking standards for Computing.
\end{abstract}

Key words: computing education, curriculum standards

\section{BACKGROUND}

Document [1] laid the foundations for the discussion and debate on benchmarking standards. This led to the formulation by the UK Quality Assurance Agency (QAA) of a requirement for experts to produce benchmarking standards for their discipline, i.e.

to produce broad statements which represent general expectations about standards for the award of honours degrees in a particular subject area. Benchmarking is not about listing specific knowledge, that is a matter for institutions in designing individual programmes. It 
is about the conceptual framework that gives a discipline its coherence and identity; about the intellectual capability and understanding that should be developed through a the study of that discipline to honours degree level; the techniques and skills which are associated with developing an understanding in that discipline; and the level of intellectual demand and challenge which is appropriate to honours degree study in that discipline.

This report describes particular aspects of the benchmarking standards for the discipline of Computing. It was produced by a Committee selected jointly by the Conference of Professors and Heads of Computing (CPIC) and the British Computer Society (BCS) as being representative of a broad range of discipline expertise from within the UK. See [2].

\section{THE TASK}

Within the academic community a wide range of terms are used to describe degrees in the subject area. Computer science, computing science, computing, software engineering, software technology, information systems, artificial intelligence, computer systems engineering and information engineering are among the more common. Indeed the Committee had to provide benchmarking standards that would accommodate in excess of 2,400 different courses. The Committee took the view that the naming of degrees would be the responsibility of individual institutions and accordingly the standards should relate to the discipline and not just degrees with specific titles.

In producing the document, the Committee was conscious of the need to involve the academic community but also to take advice from the professional bodies (including the British Computer Society, the Institution of Electrical Engineers, the Software Engineering Association, the Academy of Information Systems and the AISB) and generally from industry and commerce as well as the public. Accordingly, a wide-ranging consultation process was used to confirm that the balance and the thrust of the document reflected agreed-upon views. Moreover, throughout the development of the standards it was deemed important to keep the academic community informed of developments as they unfolded. A web site was set up to inform interested parties. 


\section{AUDIENCE}

The final Benchmarking Standards document had to meet the needs of four particular groups at least. These were the academic reviewers who would carry out reviews of departments, the general public who wish to be informed about the discipline, course developers, and finally external examiners. The manner in which the Committee set out to address these needs is given below.

\subsection{Academic Review}

Ultimately this process of academic review would involve an assessment of each Computing department in the UK; academic reviewers would have to make judgements about whether degree courses met the standards and had to be given guidance on how to address these benchmarking standards

\subsection{The Public}

To be accessible to a wide audience the standards had to be couched in language that was non-technical and non-threatening; yet, it was important to convey the sense of a new and exciting discipline that had the potential to open up a wide range of possibilities for study and future career opportunities

\subsection{Course Developers}

To stimulate the design and development of new and imaginative courses the Committee included a section on diversity of course provision; in addition, the standards were phrased in a manner intended to encourage novelty and not to constrain unduly

\subsection{External Examiners}

For this group (who as visitors to departments would have to agree to and preside over the awards of degrees) it was decided that guidance would be provided in terms of what should be sought, for example, in reviewing examination papers, in looking at final year projects, in guidelines that might apply for examination boards and so on. It was specifically not the intention that the benchmarking standards would be used when considering, for example, the award to each individual student 


\section{ISSUES}

A variety of issues caused the Committee a great deal of debate. Below five of these are highlighted.

\subsection{Title of Discipline}

Originally the Committee had been charged with producing benchmarking standards for the discipline of Computer Science. Consultation with the community produced an overwhelming reaction to the title and asked that this be changed to Computing. This change occurred.

\subsection{Rate of Change}

Given the nature of the discipline, and the rapid developments that are causing regular changes to the curriculum and the method of teaching, it is to be expected that curricula in Computing will have to change on a regular basis. To address this, the benchmarking standards were written without reference to specific details of today's technologies. In the longer term the benchmarking statements themselves would need to be reviewed. For those undertaking any revision, the thinking of the initial committee would be relevant. Accordingly, a rationale document was produced. More generally, it was hoped that all the academic community would find this of value since it provides insight into the processes that underlie everything to do with benchmarking activity.

\subsection{Considerations on Core Content}

In considering the issue of course design, one central concern was whether there should be core material that would be common to all courses. To include a core would tend to constrain thinking and to limit diversity. Yet, there is some very basic material that surely everyone should know. In exploring thoughts in this area, it appeared that this material was largely either

- skills based, and could be captured under the heading of IT skills, or

- it related to the crucial areas of requirements, specification, design, implementation, maintenance.

Indeed this was the approach used. 


\subsection{Body of Knowledge}

In their deliberations, the committee produced a body of knowledge that was intended to outline the breadth of the discipline. There was great debate about what role, if any, this should play. Should it appear in the main text, should it be an annex, should it be present at all? In the end, the Body of Knowledge appears as an Annex. But, the concerns of the committee, i.e. that this would be interpreted as curricula, remain a concern.

\subsection{Benchmarking Standards}

The QAA had insisted only that the committee articulate a set of criteria for threshold levels. This was to be interpreted as the gaining of an honours degree. The committee felt that, in the interests of the public perceptions of the subject and encouraging excellence, this alone would not reflect the best interests of the discipline. Accordingly, a decision was made to define modal standards also and to make comments about requirements that should apply for the best students.

\section{TOWARDS BENCHMARKING STANDARDS}

In considering their remit, the committee felt that it should set out a number of fundamental aims and objectives, which could then guide their thinking.

\subsection{Basic Considerations}

Computing should be presented as a discipline in which -teaching and learning was characterised by a blend of knowledge (including underpinning as well as the principal methods and methodologies), understanding, practical work, appreciation of applications and attitudes. Practical activity should reflect a disciplined approach that includes a careful blending of skills underpinned by theory as well as the application of methods and methodologies, and the use of tools in support of these applications.

Within courses, there should be encouragement for creativity and innovation, as well as active learning. Assessment should reflect this as well as a problem solving approach. Courses must be up-to-date (students are viewed as agents of technology transfer) in terms of content (practices of the subject including skills) and equipment (software, hardware, communications, etc.). Courses need also to be relevant to the modern world 
and include attention to communications skills, teamwork, IT and numeric skills as well as life-long learning. In addition, there should be an element of flexibility to address student choice, especially in the later stages of a course.

\subsection{Characteristics of Benchmarking Standards}

Benchmarking Standards in Computing would have to

- accommodate a wide variety of courses

- capture the essence of Computing, and present a consistent philosophy about the nature of the discipline

- take account, where appropriate, of the engineering ethos, and provide no conflict with accreditation criteria

- encourage innovation and creativity in course provision, as well as better courses

- ensure up-to-date provision, and take account of the needs of industry (and be relevant)

In addition they should

- accommodate modular provision, joint courses, etc.

- be meaningful, accommodate levels and ideally be succinct

- reflect student achievement (and include attention to progress rates)

- accommodate assessment against standards which must be straightforward and unambiguous

By contrast, the benchmarking standards in Computing should not

- be technology dependent or date quickly

- lead to national curricula

- limit diversity or stifle the development of new courses

- confuse accreditation and quality assessment which are different

- favour one kind of approach, e.g. hardware or software, formal or informal, highly theoretical

- be bureaucratic or create revolution

- relate purely to difficulty or to the purely academic. 


\section{FINAL REPORT}

\subsection{Structure}

In the end, the structure of the Benchmarking Standards document was as follows:

1. The Study of Computing

2. The Curriculum

2.1 The cognate area

2.2 Abilities and skills

3. Course design

3.1 Principles of course design

3.2 Themes

3.3 Diversity of provision

4. Learning, teaching and assessment

4.1 Learning and teaching

4.2 Student motivation

4.3 Student induction

4.4 Assessment issues

4.5 Learning environments and resources

5. Benchmarking standards

5.1 Threshold

5.2 Modal

Annex A Body of Knowledge

\subsection{Commentary}

It seemed inadvisable to separate out teaching and learning from assessment. The maxim that 'assessment guides learning' is particularly apposite in this regard. Consequently, the three topics of teaching, learning and assessment are grouped together and addressed within the one section. 
In outlining a number of knowledge areas and skills to be acquired, the committee were conscious of the possible adverse affects of a large assessment load. Novel ways had to be found of countering such developments and, as a result, section 4.4 raises the concerns and encourages novel ways of addressing the issues.

In the same vein, the committee took the view that student motivation is a very important matter and likewise student induction; the latter implies conditioning the expectation and providing guiding. The implication is that there should be an expectation that departments would need to address these important matters.

A final comment here relates to the issue of whether the standards are demanding. Certainly for traditional Computer Science degrees, for instance, there will be an expectation of a mathematical underpinning, a rigorous approach, appropriate attention to the usual design skills and professional attitudes, as well as experience of conducting a major project. The section on themes states

Courses need to be designed to possess themes that ensure students are equipped to contribute to the development of major components of computer systems in a manner that ensures they are fit for the purpose for which they were intended.

It is important to remember that these benchmarking standards are minimal standards to be reached by all honours degree courses.

\subsection{Illustration}

To illustrate the resulting standards, the modal standards are reproduced below. It should be noted that there are additional requirements, e.g. the existence of themes within the body of knowledge to ensure depth, attention to the lifecycle phases (of requirements, specification, etc.), attention to professional and ethical issues, the acquisition of certain skills and so on. Within that context, the following is illustrative of certain key features.

\subsubsection{Modal standard}

Students reaching this will be able to:

- demonstrate a sound understanding of the main areas of the body of knowledge within their programme of study, with an ability to exercise critical judgement across a range of issues; 
- critically analyse and apply a range of concepts, principles and practices of the subject in an appropriate manner in the context of loosely defined scenarios, showing effective judgement in the selection and use of tools and techniques;

- produce work involving problem identification, the analysis, the design and the development of a system, with accompanying documentation. The work will show problem solving and evaluation skills, draw upon supporting evidence and demonstrate a good understanding of the need for quality;

- demonstrate transferable skills with an ability to show organised work as an individual and as a team member and with minimum guidance;

- apply appropriate practices within a professional and ethical framework and identify mechanisms for continuing professional development and life long learning;

- explain a wide range of applications based upon the body of knowledge.

\section{FINAL REMARKS}

The main test of these benchmarking standards will occur when they are used 'in anger', i.e. to carry out assessments of individual departments. This has now happened and the feedback is positive. Indeed, they have now been used to guide benchmarking activity in other disciplines and they also form the basis of revised accreditation criteria as used by the UK professional bodies.

A new activity is now about to commence, namely the difficult task of benchmarking Masters courses in Computing.

\section{ACKNOWLEDGEMENTS}

The work reported here owes everything to the ideas and contribution of the other members of the Benchmarking Panel, namely John Arnott, David Budgen, Peter Capon, Gordon Davies, Peter Hodson, Elizabeth Hull, Gillian Lovegrove, Paul McGrath, Keith Mander, Arthur Norman, Stanley Oldfield, Vic Rayward-Smith, Anne Rapley, Dan Simpson, Aaron Sloman, Frank Stowell and Neil Willis. 


\section{REFERENCES}

[1] The Report of the National Committee of Inquiry into Higher Education, chaired by Lord Dearing, published by HMSO, London, 1997.

[2] Computing, Benchmark Standard published by the UK Quality Assurance Agency, Gloucester, England, 2000 